\title{
Patient-centred approaches for the management of unpleasant symptoms in kidney disease
}

\section{Kamyar Kalantar-Zadeh (D), Mark B. Lockwood (D), Connie M. Rhee, \\ Ekamol Tantisattamo, Sharon Andreoli, Alessandro Balducci, Paul Laffin, Tess Harris (1), Richard Knight, Latha Kumaraswami, Vassilios Liakopoulos (1), Siu-Fai Lui, Sajay Kumar, Maggie Ng, Gamal Saadi, Ifeoma Ulasi, Allison Tong and Philip Kam-Tao Li@}

Abstract | Patients with chronic kidney disease (CKD) frequently experience unpleasant symptoms. These can be gastrointestinal (constipation, nausea, vomiting and diarrhoea), psychological (anxiety and sadness), neurological (lightheadedness, headache and numbness), cardiopulmonary (shortness of breath and oedema), dermatological (pruritus and dry skin), painful (muscle cramps, chest pain and abdominal pain) or involve sexual dysfunction, sleep disorders and fatigue. These symptoms often occur in clusters, with one of them as the lead symptom and others as secondary symptoms. Uraemic toxins (also called uremic toxins) are often considered to be the main cause of CKD-associated symptom burden, but treatment of uraemia by dialysis often fails to resolve them and can engender additional symptoms. Indeed, symptoms can be exacerbated by comorbid conditions, pharmacotherapies, lifestyle and dietary regimens, kidney replacement therapy and ageing. Patients with kidney disease, including those who depend on dialysis or transplantation, should feel actively supported in their symptom management through the identification and targeting of unpleasant symptoms via a tailored palliative care approach. Such an approach may help minimize the burden and consequences of kidney disease, and lead to improved patient outcomes including health-related quality of life and better life participation.

The critical role of patient-centredness in the management of all disease states, including chronic kidney disease (CKD), has gained increased recognition in the past decade ${ }^{1,2}$. This turning point has led to heightened interest in symptom science, and in the field of nephrology, a focus on effective symptom management ${ }^{3}$. Symptom management was a well established discipline prior to the invention of dialysis therapy over five decades ago; however, the premise of contemporary symptom science in nephrology is somewhat different. Rather than focusing on the management of disease-associated symptoms, symptom science is largely based on patient preferences, with a focus on patients' perception of the unpleasant symptoms that cause suffering despite adequate pharmacotherapy and/or dialysis treatment, and that affect well-being and health-related quality of life ${ }^{4}$. Despite the importance of symptoms to quality of life and overall well-being, effective symptom management using a symptom science approach is not widely implemented in the care of patients with CKD, including those receiving dialysis, because of major knowledge gaps regarding the patterns of symptom burden and severity of unpleasant symptoms; a lack of practical tools for the assessment and appraisal of symptoms; and a lack of optimal interventions with which to alleviate unpleasant symptoms and symptom clusters in this population. We note that the term 'symptom science' is often used interchangeably with 'patient-centredness' but these terms are not equivalent; 'patient-centredness' refers to the prioritization of patients' preferences, which almost invariably includes effective management of unpleasant symptoms, whereas 'symptom science' refers to the understanding of holistic mechanisms by which symptoms are experienced and includes integrated management strategies for unpleasant symptoms (discussed below).

Our fundamental understanding and prioritization of symptom management in nephrology has been overshadowed by the multitude of technical and biomedical aspects of CKD pharmacotherapies, dialysis treatment approaches and kidney transplantation, as well as the erroneous assumption that interventions for uraemia, such as kidney replacement therapy, improve symptoms sufficiently to negate the need for additional interventions to alleviate symptoms. In addition, many nephrologists may not take ownership of symptom management ${ }^{5,6}$. Indeed, while symptom management has long been a key component in the management of other chronic diseases, particularly in the fields of oncology and palliative medicine, it is not necessarily a focus of nephrologists ${ }^{7}$. However, symptom burden can adversely affect the quality of life of patients with kidney disease, particularly when combined with regimented management approaches, including dietary and fluid restrictions, high pill burden and strict dialysis schedules ${ }^{8}$. Hence, a major unmet need exists for effective symptom management in CKD, as a means of alleviating patient suffering, improving quality of life and ensuring the overarching goal of living well with kidney disease $^{1}$. In this Perspective, we examine the concept and scope of symptom burden in CKD; theoretical frameworks and constructs for symptom science; biological mechanisms underlying some of the unpleasant symptoms associated with CKD; validated tools for symptom appraisal and assessment; and strategies for symptom management, including palliative care approaches for patients with CKD under conservative management or receiving kidney replacement therapy. 


\section{Symptom science}

In clinical medicine, a 'symptom' is defined as a self-reported or subjective perception of an individual's experience of a physical disturbance or disease. Symptoms can include processes such as pain, fatigue or pruritus ${ }^{9}$, and differ from 'signs', which are objective findings by a clinician, such as elevated blood pressure. An 'unpleasant' symptom is a symptom that is self-perceived and reported as a cause of suffering, for which patients often seek effective management. The emerging field of symptom science aims to advance knowledge of the behavioural and biological mechanisms underlying symptoms and to create patient-centred approaches and interventions with which to appraise symptoms accurately and alleviate the symptom burden, particularly in under-served populations ${ }^{10,11}$. Symptom science focuses on symptom experiences, rather than diseases and illnesses, and is becoming increasingly important as the lifespan of individuals with multiple chronic illnesses increases with the use of life-sustaining interventions, such as dialysis ${ }^{7}$. Living with these illnesses includes the management of the symptoms that accompany them. In addition, advances in technologies such as genomics, proteomics and bioinformatics have emerged as strategies to align symptom science with strategies for precision medicine, which in the future, may enable management strategies to be tailored better to individual patients and patient groups ${ }^{12,13}$.

A key concept of symptom science is the recognition that many symptoms, such as pain, depression, anxiety, depression and sleep dysfunction are shared across ailments, and thus patient-centred interventions that are applicable to one discipline may translate to others ${ }^{14}$. Although symptoms can occur in isolation, they often occur in clusters. A 'symptom cluster' is defined as three or more unpleasant symptoms that occur together and may be related through a common aetiology or mechanism, shared variance or a common outcome. One such example is the depression-fatigue-pain symptom cluster that has been described in patients with cancer ${ }^{15,16}$. The totality of symptoms, including their effect on patients' health-related quality of life and ability to participate in life, is described as the 'symptom burden' ${ }^{17,18}$. 'Symptom appraisal' involves the patient-centred assessment of symptoms that account for help-seeking behaviour (that is, how an individual patient interprets and responds to their symptoms), which can vary according to the comorbidity of interest and across the lifespan of the patient, as well as with race and ethnicity, socioeconomic status, culture and spiritual beliefs, and between rural versus urban and under-served versus privileged communities.

The field of symptom science encompasses the concepts of patient-centredness, symptom clusters, symptom burden and symptom appraisal, with the goal of developing tools and strategies that enable accurate and reproducible symptom assessment. The development of effective interventions for effective symptom management may include integrated symptom palliation strategies that may differ from more traditional therapeutic approaches, which target aetiological and mechanistic disease pathways. In recent years, the role of symptom science in the management of chronic disease states, such as cancer survivorship, has gained increased recognition. As patients with chronic, multimorbid conditions live longer and are therefore more likely to develop symptom clusters, the field of symptom science is expected to gain recognition as an approach to improving health-related quality of life ${ }^{19}$.

\section{Symptom burden from kidney disease} Individuals with CKD include those with reduced kidney function as determined by an estimated glomerular filtration rate (eGFR) $<60 \mathrm{ml} / \mathrm{min} / 1.73 \mathrm{~m}^{2}$ or abnormally high albuminuria $(>30 \mathrm{mg} / \mathrm{g})^{20}$. We note that symptoms in individuals with CKD can be disease-related, but can also be iatrogenic that is, resulting from medical interventions, including pharmacotherapy and dialysis treatment. A clear-cut distinction between disease-related and treatment-related symptoms is not always possible.

Individuals with early-stage $\mathrm{CKD}-$ that is, stages 1 to $3 a$ (eGFR $>45 \mathrm{ml} / \mathrm{min} /$ $1.73 \mathrm{~m}^{2}$ ) without substantial proteinuria - are often symptom-free or have mild symptoms, such as foamy-urine-related or mild-to-moderate proteinuria $(<500 \mathrm{mg} /$ day $)$ or nocturia as a consequence of isosthenuria (TABLE 1). However, many individuals with early-stage CKD or who are at risk of $\mathrm{CKD}$, such as those with obesity, diabetes mellitus and hypertension ${ }^{21}$, may have symptoms related to their underlying disease, including neuropathic or other pain, sensory disruptions and gastrointestinal symptoms from diabetic neuropathy; visual disturbances from diabetic or hypertensive retinopathy; and respiratory symptoms and sleep problems including obstructive sleep apnea caused by obesity. Moreover, the aetiological association between CKD and cardiovascular disease results in the potential for additional symptoms related to congestive heart failure, ischaemic heart disease or peripheral vascular disease, even in patients with early-stage $\mathrm{CKD}^{22}$. We note that specific kidney diseases may be associated with additional symptom burden, such as back pain, bleeding or infection resulting from renal cyst rupture in patients with polycystic kidney disease, or symptom clusters related to autoimmune disorders in patients with immunity-mediated kidney diseases such as lupus nephritis ${ }^{23}$.

As kidney disease progresses, symptom burden may worsen (FIG. 1; TABLE 1; Supplementary Fig. 1). The average number of symptoms in patients with kidney failure, and the distress caused by high symptom burden are similar to those experienced by patients with terminal malignancies, affecting daily living and resulting in poor health-related quality of life and loss of productivity ${ }^{17}$. Some common CKD-associated symptoms include facial oedema in the morning and lower-extremity oedema later during the day, which can progress to anasarca; pulmonary vascular congestion, leading to respiratory symptoms and limitations on physical function; and uraemic symptoms, including pruritus, fatigue, muscle cramps, restless legs, cognitive dysfunction, decreased taste and appetite and other gastrointestinal symptoms, sexual dysfunction and bleeding diatheses (TABLE 2; FIG. 1; Supplementary Fig. 2$)^{24}$.

The initiation of dialysis can also lead to the development of de novo symptoms, including pain from vascular access cannulation; orthostasis, muscle cramps or headache from excess volume removal and electrolyte fluctuations; post-dialysis fatigue; and worsening cardiovascular symptoms such as chest pain due to intra-dialytic hypotension ${ }^{2,3}$. Differential symptoms may also be experienced with specific dialysis modalities, such as abdominal discomfort and a sensation of fullness from peritoneal dialysis $^{25}$. Furthermore, medications prescribed for kidney transplantation can be associated with adverse symptoms such as headache, hirsutism, gingival hyperplasia, hyperhidrosis, and pruritis (from calcineurin inhibitors); nausea, vomiting, abdominal pain and diarrhoea (from mycophenolate mofetil); and acne, vision changes, myopathy, increased appetite, weight gain and insomnia (from steroids), as well as an increased susceptibility to infections as a consequence of immunosuppression ${ }^{26}$. 
Table 1 | Symptoms associated with chronic kidney disease

\begin{tabular}{|c|c|}
\hline CKD stage ${ }^{a}$ & Disease severity \\
\hline $\begin{array}{l}\text { No CKD as defined by } \\
\text { KDIGO guidelines, although } \\
\text { hyperfiltration }(\mathrm{eGFR} \\
\left.>120 \mathrm{ml} / \mathrm{min} / 1.73 \mathrm{~m}^{2}\right) \text { is } \\
\text { often pathological }\end{array}$ & $\begin{array}{l}\text { Normal kidney function (eGFR } \\
\left.>60 \mathrm{ml} / \mathrm{min} / 1.73 \mathrm{~m}^{2}\right) \text {, although } \\
\text { hyperfiltration }(\mathrm{eGFR}>120 \mathrm{ml} / \\
\text { min } / 1.73 \mathrm{~m}^{2} \text { ) can be present. } \\
\text { No proteinuria, but obesity, } \\
\text { diabetes, hypertension or } \\
\text { solitary kidney can be present }\end{array}$ \\
\hline
\end{tabular}

Stage 1 (eGFR $>90 \mathrm{ml}$ $\mathrm{min} / 1.73 \mathrm{~m}^{2}$ ) or Stage

2 (eGFR 60 to $<90 \mathrm{ml} /$ $\mathrm{min} / 1.73 \mathrm{~m}^{2}$ )

Stages 3a (eGFR 45 to $<60 \mathrm{ml} / \mathrm{min} / 1.73 \mathrm{~m}^{2}$ ) or $3 \mathrm{~b}$ (eGFR 30 to $<45 \mathrm{ml} /$ $\mathrm{min} / 1.73 \mathrm{~m}^{2}$ )

Stages 4 (eGFR 15 to $<30 \mathrm{ml} / \mathrm{min} / 1.73 \mathrm{~m}^{2}$ ) or 5 Advanced CKD Normal kidney function (eGFR $>60 \mathrm{ml} / \mathrm{min} / 1.73 \mathrm{~m}^{2}$ ) with moderate (A2) or more severe (A3) albuminuria

Mild to moderate CKD without substantial proteinuria $(<0.3 \mathrm{~g} /$ day $)$

$\left(\mathrm{eGFR}<15 \mathrm{ml} / \mathrm{min} / 1.73 \mathrm{~m}^{2}\right)$

Usually, stage 5, although dialysis may be initiated at higher eGFR

Kidney failure (ESRD), requiring transition to dialysis therapy

\section{Source of symptom burden}

Symptoms are related to underlying conditions, such as obesity, diabetes mellitus, polycystic kidneys or uncontrolled hypertension

Mild symptoms, such as foamy urine or nocturia, or more severe symptoms such as facial or peripheral oedema, anasarca and other symptoms related to proteinuria

Patients may have minimal symptoms, but some may report severe symptoms, including fluid retention (such as oedema of lower extremities) and dyspnea. Secondary hypertension may arise and result in symptoms if uncontrolled. latrogenic symptoms include constipation from restricted dietary potassium limiting fresh fruits and vegetables. Growth retardation may occur in children

More severe symptoms are often observed, including worsening oedema and other symptoms from fluid retention. Additional symptoms include pruritus, easy fatiguability, muscle cramps at night, restless extremities, alterations in mental state, diurnal somnolence, memory and concentration disorders, disturbed taste and smell, diminished appetite, nausea and vomiting

Symptom deterioration may prompt abrupt or incremental transition to dialysis, including decompensated heart failure, uraemic encephalopathy, refractory hiccups, peripheral neuropathy, uraemic fetor, bleeding events such as gum bleeding or gastrointestinal bleeding from platelet dysfunction, pericarditis, dry skin, uraemic frost, amenorrhea, sexual dysfunction, bone deformities, spontaneous bone fractures and ligament ruptures, weight loss, muscle wasting, and symptoms related to electrolyte and mineral disarray, such as hypocalcaemia and hyperkalaemia

Stage 5 on dialysis

Prevalent kidney failure (ESRD) status, undergoing chronic dialysis therapy with minimal to no residual renal function

In addition to the above, symptoms related to dialysis treatment include post-dialysis light-headedness and fatigue, worsening cramps during dialysis treatment, malnutrition (with muscle wasting and weight loss leading to frailty) and worsening cardiovascular symptoms such as palpitations or chest pain. Blood infection may lead to fever, hypothermia and shaking chills

In addition to symptoms associated with CKD stage, additional unpleasant symptoms can result from immunosuppressive medication. Immunosuppression may lead to higher rates of infection events and cancer with associated symptoms. Steroid therapy may lead to Cushingoid syndrome and related symptoms

\section{Unpleasant symptoms}

Neuropathic pain from diabetes; sleep disorders including snoring and sleep apnea from obesity; and kidney cyst pains are often reported.

Foamy urine can cause anxiety; nocturia disturbs sleep; facial oedema can have a psychosocial impact

Leg oedema can be uncomfortable. Shortness of breath including upon exertion (exertional dyspnea) can interfere with day-to-day activities. Orthopnea interferes with sleep. Chronic or recurrent constipation is often reported as an unpleasant symptom

Reported symptoms are frequently perceived as unpleasant and are considered a major cause of suffering. Pruritus may interfere with day-to-day activities and sleep. Worsening fatigue may interfere with productivity at work and education

Unpleasant symptoms are often most severe at the time of transition to dialysis but may gradually subside with dialysis therapy. An abrupt (outright thrice weekly) rather than incremental (once or twice weekly) transition to haemodialysis may introduce additional unpleasant symptoms such as muscle cramps, post-dialysis fatigue and orthostatic symptoms

Unpleasant symptoms related to dialysis therapy can emerge as described above. Additional unpleasant symptoms such as dry skin and needle pain from arteriovenous fistula cannulation

Immunosuppressive symptoms include tremor, gum hypertrophy, hair loss, hypertrichosis, nausea and vomiting, and fatigue

${ }^{\mathrm{a}} \mathrm{A} 1, \mathrm{~A} 2$ and $\mathrm{A} 3$ refer to the severity of albuminuria as defined by KDIGO. A2, $30 \mathrm{mg} / \mathrm{g}$ to $<300 \mathrm{mg} / \mathrm{g} ; \mathrm{A} 3,>300 \mathrm{mg} / \mathrm{g}$ CKD, chronic kidney disease (not receiving kidney replacement therapy); eGFR, estimated glomerular filtration rate; ESRD, end-stage renal disease (the USA statutory designation for kidney failure). 
Increasing burden of uraemic symptoms

Mild symptoms
and those
relating to
underlying
comorbidities
- Sleep disorders
- Facial or
peripheral
oedema

Variable
symptoms
- Anxiety
- Depression
- Worsening
oedema
- Constipation

More severe symptoms
- Fluid overload
- Pruritus
- Fatigue
- Muscle cramps
- Restless legs
- Cognitive
dysfunction
- Nausea and vomiting

Stages 1-2
Symptom deterioration

- Cardiopulmonary symptoms

- Gastrointestinal symptoms

Worsening uraemic symptoms

- Cognitive Bleeding

dysfunction diatheses

- Anorexia - Worsening

- Sexual dysfunction pruritus

\begin{tabular}{|c|c|c|c|}
\hline Stages 1-2 & Stage 4 & \multicolumn{2}{|c|}{ Stages $5,5 \mathrm{D}$ and $5 \mathrm{~T}$} \\
\hline & $\begin{array}{l}\text { Preparation for } \\
\text { transition to kidney } \\
\text { replacement } \\
\text { therapies }\end{array}$ & \multirow{2}{*}{$\begin{array}{l}\text { Dialysis-associated } \\
\text { symptoms } \\
\text { - Light-headedness } \\
\text { and fatigue } \\
\text { - Cramps } \\
\text { - Malnutrition, muscle } \\
\text { wasting and frailty } \\
\text { - Worsening } \\
\text { cardiovascular } \\
\text { symptoms } \\
\text { - Blood infection- } \\
\text { related symptoms }\end{array}$} & \multirow{2}{*}{$\begin{array}{l}\text { Immuno- } \\
\text { suppression- } \\
\text { associated } \\
\text { symptoms } \\
\text { (in transplant } \\
\text { recipients) } \\
\text { - Increased risk of } \\
\text { infection-related } \\
\text { symptoms } \\
\text { - Hypertrichosis } \\
\text { - Nausea and } \\
\text { vomiting }\end{array}$} \\
\hline $\begin{array}{l}\text { Pharmacotherapy } \\
\text { - Alternative therapies; } \\
\text { diet and lifestyle modification }\end{array}$ & $\begin{array}{l}\text { Conventional } \\
\text { dialysis transition } \\
\text { - Incremental } \\
\text { dialysis } \\
\text { transition } \\
\text { - Pre-emptive } \\
\text { transplantation }\end{array}$ & & \\
\hline
\end{tabular}

Kidney-preserving therapies and effective symptom management may delay dialysis and transplantation

Palliative care, supportive care, hospice

CKD symptoms Treatment-associated symptoms

Fig. 1 | The burden of unpleasant symptoms across progressive stages of chronic kidney disease. The burden of unpleasant symptoms increases with progression of chronic kidney disease (CKD), and includes the emergence of symptoms associated with treatments such as dialysis and immunosuppressive therapy. Pharmacotherapy and alternative therapies may alleviate symptom burden and delay disease progression. Initiation of kidney replacement therapies requires preparation, depending on the symptom burden, disease stage and other factors. The development of effective interventions for effective symptom management may also include integrated symptom palliation strategies, supportive care and hospice care approaches that may differ from more traditional therapeutic approaches. Stage 5D, dialysis; stage 5T, transplant.

\section{Theoretical frameworks}

Understanding unpleasant symptoms in the context of a theoretical framework is essential to advancing symptom science in CKD and to achieving the important goal of living well with kidney disease through effective symptom management ${ }^{27}$. These theoretical frameworks explicitly state concepts and assumptions related to symptom science, allowing researchers and clinicians to evaluate them critically and objectively for given applications in the management of patients with CKD. So far, the field of symptom management and research has predominantly focused on three theoretical frameworks: the theory of unpleasant symptoms (TOUS); the University of California San Francisco (UCSF) symptom management theory; and the National Institutes of Health (NIH) symptom science model (FIG. 2; Supplementary Table 1).

\section{The theory of unpleasant symptoms.} TOUS provides a framework with which to inform our understanding of individual symptoms and contributing factors that may guide interventions aimed at reducing or eliminating symptom burden ${ }^{28}$. It takes a holistic view of the patient, recognizing the complexity of symptoms and the notion that multiple symptoms might be connected via mechanistic feedback loops, to enable examination of common symptom clusters ${ }^{28}$. The TOUS framework identifies three categories of factors that influence symptom experience: physiological (including age, sex and factors that are illness-specific), psychological (for example, mood, cognition and health literacy), or situational (for example, social and physical environmental factors and other external factors ${ }^{29}$. Importantly, the theory also considers environmental, social, cultural and spiritual factors that may influence an individual's symptom experience ${ }^{28}$. TOUS presumes that the symptoms consequently affect an individual's performance, which can in turn feed back to influence the symptom experience (FIG. 2a). Although examples of the application of TOUS to symptom science in CKD are limited, at least one study has used TOUS as a framework to understand symptom clusters in patients with CKD and serves as an excellent example of how TOUS can be applied to symptom science in kidney disease ${ }^{30}$. In that study, symptom clusters had a strong negative effect on the health-related quality of life of 436 patients with advanced CKD, with fatigue, sexual symptoms and restless legs being the strongest predictors. Overall, the model explained more than half of the deterioration in health-related quality of life, although a reciprocal path between quality of life and symptom experience was not found ${ }^{30}$.

\section{The UCSF symptom management theory.}

The UCSF symptom management theory has been validated in several non-kidney disease conditions associated with symptom clusters ${ }^{31,32}$. This theory identifies three central concepts: symptom experience, symptom management and symptom outcomes (FIG. 2b) $)^{33}$. Symptoms are considered from the point of view of the individual's personal experience, with the understanding that the perception of symptoms might be influenced by physiological, psychological and contextual or environmental factors ${ }^{32}$. Unlike TOUS, which assumes the existence of feedback loops between symptom experience and performance, the UCSF symptom management theory considers that the three main concepts (symptom experience, symptom management and symptom outcomes) are connected via directional links, which can be targeted to reduce symptom burden. Cost considerations are also included in this model ${ }^{32}$. Although we are not aware of any examples in which the UCSF symptom management theory has been applied to kidney care, this model has promising aspects that are relevant to patients with CKD (Supplementary Table 1).

The NIH symptom science model. The NIH symptom science model follows a systematic, stepwise process to identify processes and outcomes that are directly relevant to patient care ${ }^{11,14}$. The model provides a framework with which to identify distinct and shared functional pathways that can be targeted to reduce the symptom burden of an individual. The inclusion of biomarker identification and validation in the model underlies the intended utility of this approach with in a precision-medicine-based health framework ${ }^{14}$. A limitation of the model that is pertinent to the care of patients with CKD is that it does not explicitly address social, environmental or personal 
Table 2 | Common unpleasant symptoms in patients with chronic kidney disease

\begin{tabular}{|c|c|c|c|}
\hline Symptoms & $\begin{array}{l}\text { Level of } \\
\text { unpleasantness }\end{array}$ & Potential causes & $\begin{array}{l}\text { Suggested palliative and management } \\
\text { interventions }\end{array}$ \\
\hline \multicolumn{4}{|l|}{ Pain } \\
\hline Muscle cramps & +++ & Electrolyte disorders, hypocalcaemia & $\begin{array}{l}\text { Monitor and correct electrolytes, effective use of pain } \\
\text { medications }\end{array}$ \\
\hline Headache & ++ & $\begin{array}{l}\text { Uncontrolled hypertension } \\
\text { Excessive ultrafiltration on dialysis }\end{array}$ & $\begin{array}{l}\text { Monitor blood pressure and avoid rebound } \\
\text { hypertension, avoid excessive ultrafiltration }\end{array}$ \\
\hline AVF/AVG cannulation pain & ++ & Needle stick & Lidocaine-based creams \\
\hline Abdominal pain & +++ & Peritonitis, pancreatitis, gastroenteritis & $\begin{array}{l}\text { Antibiotic treatment of peritonitis, gastrointestinal } \\
\text { therapies }\end{array}$ \\
\hline Neuropathic pain/discomfort & +++ & Uraemic or diabetic & Anti-neuropathy medications such as gabapentin \\
\hline Kidney cyst pain & ++ & $\begin{array}{l}\text { Cyst bleeding and/or infection, } \\
\text { generalized back pain/perirenal pain }\end{array}$ & $\begin{array}{l}\text { Urological/interventional radiology management, } \\
\text { surgery, effective pain management including } \\
\text { potential nerve blocks }\end{array}$ \\
\hline $\begin{array}{l}\text { Cardiovascular pain: chest } \\
\text { pain, claudication }\end{array}$ & ++ & $\begin{array}{l}\text { Cardiovascular disease, vascular } \\
\text { calcification }\end{array}$ & $\begin{array}{l}\text { Cardiovascular management, symptomatic therapies, } \\
\text { avoid excessive ultrafiltration/diuresis }\end{array}$ \\
\hline Bone pain & + & sHPT, osteoporosis & $\begin{array}{l}\text { Effective therapies for sHPT, minimize fracture risk by } \\
\text { adjusting lifestyle }\end{array}$ \\
\hline Joint pains & ++ & Osteoarthritis, amyloidosis & $\begin{array}{l}\text { Effective pain management, complementary } \\
\text { therapies, such as acupuncture }\end{array}$ \\
\hline \multicolumn{4}{|l|}{ Gastrointestinal symptoms } \\
\hline Taste and smell disturbances & + & Uraemia & $\begin{array}{l}\text { Correct uraemia, enforce coping mechanisms, dietary } \\
\text { counselling }\end{array}$ \\
\hline Diminished appetite & + & Uraemia, depression, high pill burden & $\begin{array}{l}\text { Reduce pills, treat depression, orexigenic agents such } \\
\text { as mirtazapine }\end{array}$ \\
\hline Nausea and vomiting & ++ & $\begin{array}{l}\text { Uraemia, diabetic gastroparesis, adverse } \\
\text { effects of medications }\end{array}$ & $\begin{array}{l}\text { More frequent smaller meals, anti-emetic } \\
\text { medications }\end{array}$ \\
\hline Diarrhoea & + & $\begin{array}{l}\text { Adverse effects of medications, } \\
\text { diabetes, infections such as Clostridium } \\
\text { difficile }\end{array}$ & $\begin{array}{l}\text { Reduce or change medications including phosphorus } \\
\text { binders, change diet or use dietary supplements }\end{array}$ \\
\hline Constipation & +++ & $\begin{array}{l}\text { Restricted dietary potassium limiting } \\
\text { fresh fruits and vegetables }\end{array}$ & $\begin{array}{l}\text { Increase intake of high-fibre foods, control } \\
\text { hyperkalaemia without restricting fruits and } \\
\text { vegetables }\end{array}$ \\
\hline Discoloured stool & + & $\begin{array}{l}\text { Gastrointestinal bleeding, iron-based } \\
\text { medication }\end{array}$ & $\begin{array}{l}\text { Correction of gastrointestinal bleeding, reassuring } \\
\text { and educating if taking iron product }\end{array}$ \\
\hline Hiccups & +++ & Probably from worsening uraemia & $\begin{array}{l}\text { Treatment of uraemia, adjunct neuroleptic and } \\
\text { medical cannabis }\end{array}$ \\
\hline \multicolumn{4}{|c|}{ Sleep problems and fatiguability } \\
\hline $\begin{array}{l}\text { Inability to sleep well or } \\
\text { enough at night }\end{array}$ & +++ & Uraemia, fluid overload & $\begin{array}{l}\text { Effective diuresis, better clearance, more frequent } \\
\text { dialysis }\end{array}$ \\
\hline Diurnal somnolence & + & Inadequate night sleep & Improving night sleep \\
\hline Snoring and/or sleep apnea & ++ & Obesity, fluid retention & CPAP including for sleep during dialysis \\
\hline Feeling tired, lack of energy & +++ & $\begin{array}{l}\text { Uraemia, anaemia, iron deficiency, } \\
\text { electrolyte disarrays, malnutrition, } \\
\text { hypothyroidism }\end{array}$ & $\begin{array}{l}\text { Correct anaemia and iron status, monitor electrolytes, } \\
\text { physical/occupational management }\end{array}$ \\
\hline Post-haemodialysis fatigue & +++ & Fluid and electrolyte fluctuations & Avoid excessive ultrafiltration during haemodialysis \\
\hline \multicolumn{4}{|l|}{ Pruritus and other skin problems } \\
\hline Dry mouth & + & $\begin{array}{l}\text { Adverse effects of medications, volume } \\
\text { depletion }\end{array}$ & Adjust medications and dosage, adjust ultrafiltration \\
\hline General body itching & +++ & $\begin{array}{l}\text { Uraemia, sHPT, anaemia, underlying } \\
\text { diseases }\end{array}$ & $\begin{array}{l}\text { Effective uraemia and sHPT therapies, effective use of } \\
\text { conventional and emerging medications }\end{array}$ \\
\hline Dry skin & +++ & Uraemia, dermatitis & Skin lotions, dermatological management \\
\hline $\begin{array}{l}\text { Excessive/sudden } \\
\text { perspiration }\end{array}$ & + & $\begin{array}{l}\text { May happen with excessive } \\
\text { ultrafiltration }\end{array}$ & Lower ultrafiltration rate, gentle dialysis \\
\hline $\begin{array}{l}\text { AVF/AVG appearance/ } \\
\text { aneurysm }\end{array}$ & ++ & Frequent cannulations & Surgical correction of aneurysm \\
\hline
\end{tabular}


Table 2 (cont.) | Common unpleasant symptoms in patients with chronic kidney disease

\begin{tabular}{|c|c|c|c|}
\hline Symptoms & $\begin{array}{l}\text { Level of } \\
\text { unpleasantness }\end{array}$ & Potential causes & $\begin{array}{l}\text { Suggested palliative and management } \\
\text { interventions }\end{array}$ \\
\hline \multicolumn{4}{|c|}{ Pruritus and other skin problems (cont.) } \\
\hline Hair loss & ++ & Uraemia, other comorbidities & Medical and nutritional therapies \\
\hline Uraemic frost & + & High urea level & Dialysis or transplantation \\
\hline \multicolumn{4}{|c|}{ Mental health and psychological symptoms } \\
\hline Anxiety & +++ & \multirow{3}{*}{$\begin{array}{l}\text { CKD burden and perception, loss of } \\
\text { control, fear of dialysis, fear of early } \\
\text { death, drug effects }\end{array}$} & \multirow{3}{*}{$\begin{array}{l}\text { Anti-anxiety medications, cognitive behavioural } \\
\text { therapy, group therapy }\end{array}$} \\
\hline Mood fluctuation & + & & \\
\hline Depression & ++ & & \\
\hline Cognitive impairment & + & $\begin{array}{l}\text { Uraemia, amyloidosis, side effects of } \\
\text { therapy }\end{array}$ & Family support, pharmacotherapy \\
\hline \multicolumn{4}{|l|}{ Other neurological symptoms } \\
\hline $\begin{array}{l}\text { Light-headedness and/or } \\
\text { orthostatic symptoms }\end{array}$ & ++ & $\begin{array}{l}\text { Excessive ultrafiltration, excessive } \\
\text { diuresis, diarrhoea, medications such as } \\
\text { alpha-blockers }\end{array}$ & Lower dialysis ultrafiltration rate, lower diuretic dose \\
\hline Restless extremities & +++ & $\begin{array}{l}\text { Uraemia, medications such as } \\
\text { antihistamines }\end{array}$ & Try pharmaco-therapies such as ropinirole \\
\hline Hypothermia & ++ & Uraemia, infection & Ensure warm environment \\
\hline Inability to walk well & ++ & Muscle wasting, protein-energy wasting & Adequate protein and energy intake \\
\hline Difficulty concentrating & + & $\begin{array}{l}\text { Often evident when performing } \\
\text { cognitive tasks, like reading }\end{array}$ & $\begin{array}{l}\text { Dialysis initiation may be indicated to improve mental } \\
\text { concentration ability }\end{array}$ \\
\hline \multicolumn{4}{|c|}{ Cardiovascular and respiratory symptoms } \\
\hline Facial puffiness & + & \multirow{2}{*}{$\begin{array}{l}\text { Fluid retention, reduced eGFR, loss of } \\
\text { residual kidney function }\end{array}$} & \multirow{2}{*}{$\begin{array}{l}\text { More effective diuresis, avoid medications and food } \\
\text { with high Na content }\end{array}$} \\
\hline Lower extremity swelling & + & & \\
\hline $\begin{array}{l}\text { Shortness of breath } \\
\text { (orthopnea and exertional } \\
\text { dyspnea) }\end{array}$ & +++ & $\begin{array}{l}\text { Congestive heart failure exacerbation, } \\
\text { pneumonia, COVID-19 }\end{array}$ & $\begin{array}{l}\text { More effective diuretic therapies, more effective } \\
\text { ultrafiltration, more frequent haemodialysis, treat URI } \\
\text { and pneumonia }\end{array}$ \\
\hline Cough & ++ & Hyperactive airway, fluid & Bronchodilators, fluid removal \\
\hline Palpitation & ++ & \multirow{2}{*}{$\begin{array}{l}\text { Excessive ultrafiltration on } \\
\text { haemodialysis or peritoneal dialysis, } \\
\text { valvular disease, arrhythmia }\end{array}$} & \multirow{2}{*}{$\begin{array}{l}\text { Cardiovascular and electrophysiological studies and } \\
\text { treatment. Reduce ultrafiltration rate }\end{array}$} \\
\hline Syncope & ++ & & \\
\hline Thrombosis symptoms & + & Deep vein thrombosis & Mobilization, anti-thrombotic therapies \\
\hline Pericardial effusion symptoms & + & Pericardial effusion & Increase dialysis adequacy \\
\hline \multicolumn{4}{|c|}{ Genitourinary and sexual symptoms } \\
\hline Foamy urine & + & Proteinuria & Low-protein diet, ACEi/ARB \\
\hline Nocturia & ++ & Isosthenuria & Avoid diuretic before sleeping \\
\hline Dysuria & ++ & UTI & Detect and treat UTI \\
\hline Ability to make urine & ++ & Reduced residual kidney function & Enforce diuretic therapies, ACEi/ARB \\
\hline Sexual dysfunction & ++ & Anaemia, uraemia, neuropathy & $\begin{array}{l}\text { Correct anaemia, enhance dialysis clearance, } \\
\text { psychosocial support }\end{array}$ \\
\hline \multicolumn{4}{|l|}{ Other symptoms } \\
\hline Muscle weakness, frailty & ++ & $\begin{array}{l}\text { Uraemic myopathy, protein-energy } \\
\text { wasting, vitamin D deficiency, } \\
\text { hypothyroidism }\end{array}$ & $\begin{array}{l}\text { Exercise regimens, nutritional support, vitamin D } \\
\text { supplements }\end{array}$ \\
\hline $\begin{array}{l}\text { Bleeding (from gum, nose and } \\
\text { so on) }\end{array}$ & ++ & Platelet dysfunction & Improving uraemia such as by dialysis \\
\hline Uraemic fetor & + & Worsening azotaemia & Dialysis or kidney transplantation \\
\hline Gum and denture symptoms & ++ & Diabetes, advanced age & Gum and dental health interventions \\
\hline
\end{tabular}

+ Mildly unpleasant; ++ moderately unpleasant; +++ extremely unpleasant. ACEi, angiotensin-converting-enzyme inhibitor; ARB, angiotensin-receptor blocker; AVF, arteriovenous fistula; AVG, arteriovenous graft; CKD, chronic kidney disease (not receiving kidney replacement therapy); CPAP, continuous positive airway pressure; eGFR, estimated glomerular filtration rate; sHPT, secondary hyperparathyroidism; URI, upper respiratory tract symptom; UTI, urinary tract infection.

factors (such as socio-economic status or racial disparities) that can contribute to an individual's symptom experience; however, these factors could potentially be considered by applying separate steps to the model (FIG. 2c; Supplementary Table 1).

\section{Symptom-based approaches in CKD} As mentioned earlier, emerging evidence demonstrates that symptoms experienced by 
those suffering from most chronic diseases, including CKD, occur in clusters ${ }^{1,19,34,35}$. Consistent with many advances in symptom science, the contemporary concept of condition-specific symptom clusters originated in the field of oncology $y^{9,36}$. Symptom clusters are generally recognized as stable groups of three or more concurrent symptoms that are related to one another, and are independent of other symptom clusters (TABLE 2) ${ }^{37}$. For instance, inability to sleep well, fatigue and depression can be caused or aggravated by pruritus. A lead symptom can result in additional unpleasant symptoms in the form of symptom clusters; for example, chronic or recurrent pruritus causes or intensifies other symptoms ${ }^{38,39}$. Interdependency between symptoms can exist, such that several symptoms may share a common underlying biological aetiology and present in the form of clusters; hence, addressing one symptom in the cluster may have synergistic effects on other symptoms and overall clinical outcomes. Several studies in patients with CKD have demonstrated an association of symptom clusters that includes depression with outcomes such as health-related quality of life and mortality ${ }^{17,34,35}$.

Two approaches that can be used to identify symptom clusters are the variable-centred approaches and person-centred approaches. Variable-centred approaches, also known as de novo clustering, seek to identify relationships between individual symptoms and have been frequently used to phenotype symptoms in $\mathrm{CKD}^{35,38,40}$. This approach can use qualitatively derived findings obtained through interviews and focus groups or quantitatively derived data obtained via comprehensive symptom instruments. One study ${ }^{41}$ used principal component analysis with varimax rotation to identify three symptom clusters - uraemic, neuromuscular and skin - from the symptom list of the Kidney Disease Quality of Life (KDQOL) instrument. Subsequent multivariate Cox regression analysis showed that the uraemic symptom cluster was predictive of all-cause mortality ${ }^{41}$. Mixed methods studies of symptom clusters highlight an emerging approach to research that involves the systematic integration of quantitative and qualitative data within a single investigation.

Variable-centred approaches to clustering symptoms are complicated by the absence of a commonly recognized instrument with which to measure symptoms. Moreover, difficulty in discerning seemingly overlapping symptom clusters and accurately interpreting their shared mechanistic pathways, owing to the heterogeneity of symptom response patterns, limits their clinical utility of variable-centred approaches $^{19,42}$. Fatigue ${ }^{43}$, sleep disturbance ${ }^{44}$, depression and/or anxiety ${ }^{45}$, pain $^{46,47}$, pruritus $^{48}$ and gastrointestinal symptoms ${ }^{49}$ are among the most common co-occurring de novo symptom clusters in CKD $(\text { TABLE 2) })^{50}$.

In the past few years a notable shift has occurred from the use of variable-centred approaches to person-centred approaches for symptom clustering. Person-centred approaches, also known as a priori clustering, assigns membership of an individual's symptoms into subgroups on the basis of similar symptom response patterns to pre-specified symptom clusters. The symptom clusters (for example, a cluster of fatigue, pain and depression) are determined by empirical evidence and measured using validated instruments for a given symptom ${ }^{51,52}$. For example, a person-centred symptom cluster analysis of data from the CRIC study ${ }^{1}$ using 11 symptom items from the KDQOL instrument used latent class analysis to classify individuals into three discrete symptom cluster subgroups - low, moderate and high symptoms - based on the symptom response pattern of individual patients at their baseline visit. Sex, comorbidities and KDQOL physical and mental composite scores were predictive of membership of the symptom cluster subgroups. This approach may represent a powerful tool with which to assess the impact of symptom experience on patient outcomes $^{19,53}$; however, more research in

\section{a The theory of unpleasant symptoms (TOUS)}

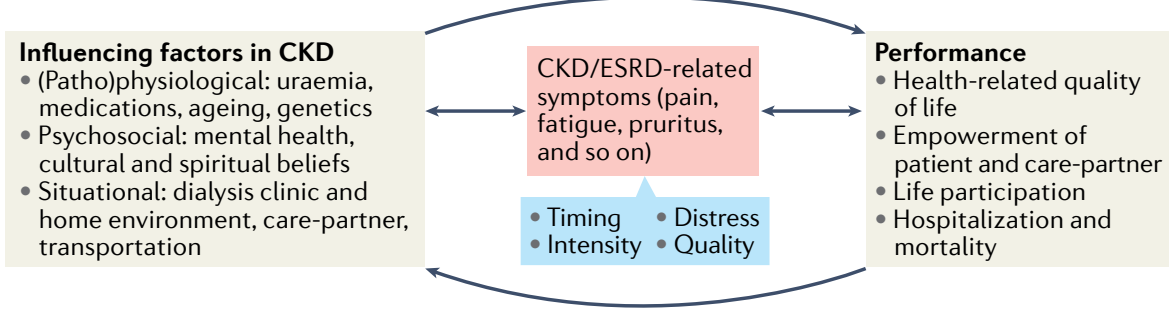

\section{b UCSF symptom management theory}
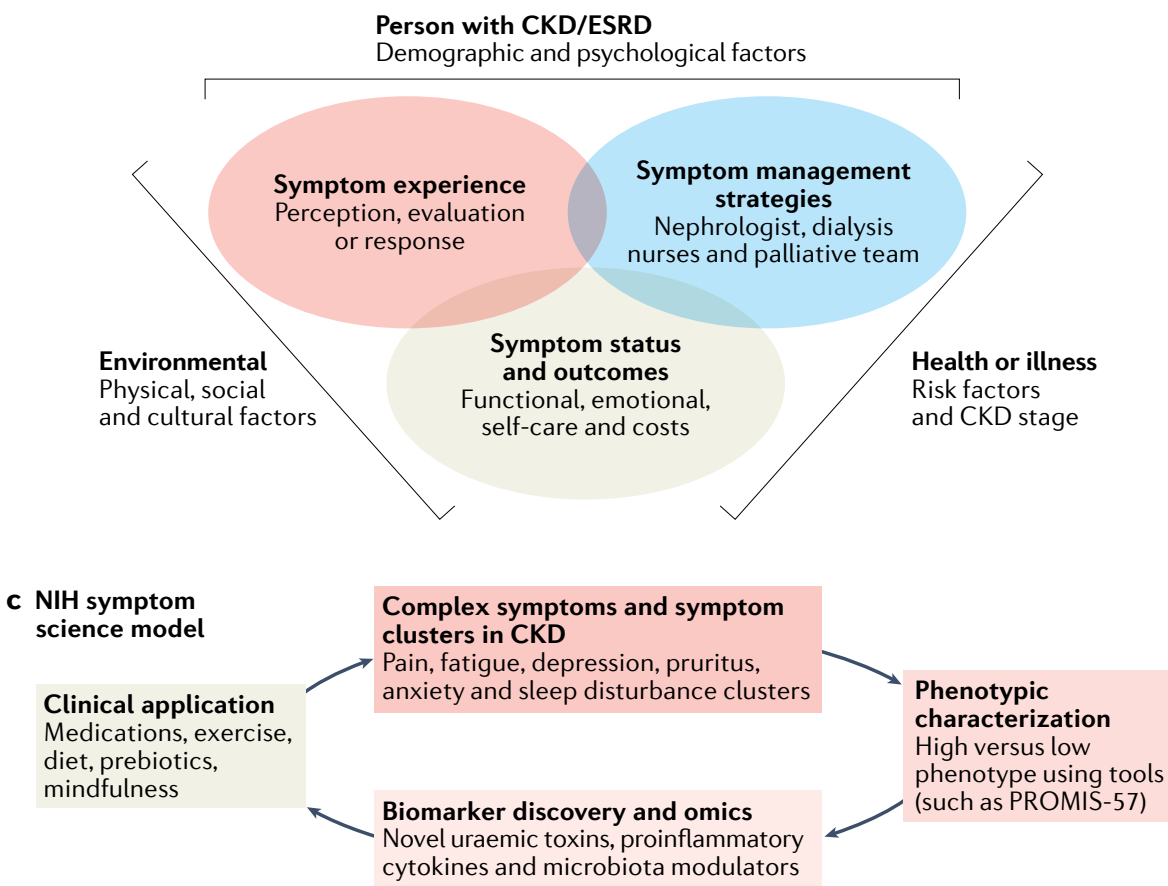

Fig. 2 | The three leading symptom science-related theoretical frameworks of unpleasant symptoms for application in the management of patients with CKD. a | Lenz's theory of unpleasant symptoms (TOUS). b | The University of California San Francisco (UCSF) symptom management theory. c| The National Institutes of Health (NIH) symptom science model. CKD, chronic kidney disease; ESRD, end-stage renal disease (also referred to as kidney failure); PROMIS-57, Patient Reported Outcomes Measurement Information System-57. 
CKD populations needed to determine whether symptom clusters can be validated and reproduced across the spectrum of $\mathrm{CKD}$ and in different settings. Moreover, further research is needed to determine how membership of symptom cluster subgroups can change over time and whether subgroup membership can predict important clinical and health utilization outcomes. Such insights are important if the available findings are to be translated into clinical practice.

Although the field of symptom clustering in $\mathrm{CKD}$ is nascent, recognition of the clinical utility of this approach in guiding personalized health strategies for diagnosis, risk stratification, management and treatment is growing. One relevant example of the utility of this framework is in the clinical management of fluid status in patients on dialysis, which largely depends on the use of distinct groups of symptoms to accurately assess volume status (Supplementary Table 2) ${ }^{54}$. A patient with fluid overload may have cardio-pulmonary symptoms from vascular congestion; facial or lower-extremity oedema; and impaired physical function as a consequence of exertional dyspnea, and hence would benefit from greater diuresis or ultrafiltration. Conversely, patients may encounter symptoms of fluid depletion, which can be iatrogenic as a consequence of excessive diuresis or ultrafiltration, and involve a typical symptom cluster comprising palpitations and/or chest pain; lightheadedness and/or orthostasis and/or gait instability; and worsening muscle cramps, particularly with large intra-dialytic fluid removals. Given that existing objective methods or 'signs' that are used to assess volume status in the clinical setting - such as blood pressure, hematocrit trends or point-of-care ultrasound (if available) - are blunt and imprecise, a routine assessment of symptom clusters might serve as an important adjunct in CKD management. Moreover, alleviating such symptom clusters should be a primary objective independent of the effects of volume status on other key outcomes, such as cardiovascular disease, as a means of reducing suffering and optimizing patient-centred care ${ }^{55,56}$. However, more research is needed to determine how best to translate symptom cluster data into clinical practice for the care of patients with CKD.

\section{Pathophysiology of CKD symptoms}

A greater understanding of the potential biological mechanisms underlying common symptoms reported by individuals with
CKD is essential for identifying targeted interventions that lessen symptom burden and improve quality of life. As symptoms often occur in clusters, they may also share a common biological aetiology $y^{1,19,30,34}$. For example, a psychoneurological symptom cluster (for example, involving pain, fatigue, anxiety, depression, pain, sleep disturbance and cognitive dysfunction) has been consistently observed among patients with cancer - a population that has a similar level of symptom experience to that of patients with advanced $\mathrm{CKD}^{57-60}$.

The biological mechanisms underlying symptom burden in CKD are multifactorial and affected by multiple comorbidities, dietary restrictions, polypharmacy, kidney replacement therapy, and the direct and indirect effects of retained uraemic toxins. The accumulation of uraemic solutes with CKD progression induces a pro-inflammatory state, which leads to the dysregulation of key metabolic and neuroendocrine signalling pathways $\mathrm{s}^{57,60,61}$. The resulting effects on noradrenergic, serotonergic and histaminergic neurons causes vascular damage in the central nervous system, which may contribute to development of psychoneurological symptoms $^{62}$.

Uraemic toxins are believed to be an important cause of many signs and symptoms in patients with advanced CKD, including anorexia, nausea, vomiting, difficulty concentrating, bleeding tendencies and pruritus. The observation that some, but not all CKD-associated symptoms improve with adequate dialysis therapy or successful kidney transplantation supports this tenet ${ }^{63}$. Theoretically, uraemia can be managed by strategies that effectively lower levels of uraemic toxins. Such therapies potentially include charcoal-based approaches, which absorb uraemic toxins ${ }^{64}$, and dietary approaches that reduce the generation of endogenous uraemic toxins ${ }^{65}$.

Fluid retention can cause distressing respiratory and cardiovascular symptoms independent of the degree of severity of uraemia. Conversely, dialysis therapy is a major contributor to symptoms of fluid depletion, such as muscle cramps and light-headedness. Haemodialysis can also cause glycaemic fluctuations, in extreme cases leading to dialysis-associated hypoglycaemia and its associated symptoms ${ }^{66}$. The adverse effects of kidney failure medications, including those used by kidney transplant recipients, and the associated pill burden can aggravate these symptoms and lead to the development of additional symptoms, such as gastrointestinal problems, tremors and sleeplessness (FIG. 1).

Other contributors to unpleasant symptoms in patients with CKD include iron deficiency and anaemia (associated with a feeling of weakness and fatigue $)^{67}$, vitamin $\mathrm{D}$ deficiency and secondary hyperparathyroidism (associated with bone pain and muscle weakness) ${ }^{68}$, hyperphosphataemia and calcium disarrays (associated with pruritus and restless limbs) $)^{69}$, metabolic disturbances, such as potassium fluctuations and acid-base disorders (associated with palpitations and symptoms related to the exacerbation of heart failure $)^{70}$, and hormonal disturbances such as hypothyroidism or sex hormone disorders (associated with hypothermia, depression, excessive vaginal bleeding and sexual dysfunction $)^{71}$.

Protein-energy wasting, along with inflammation and oxidative stress, can cause muscle weakness, fatigue and frailty in patients with $\mathrm{CKD}^{72}$. A 2020 study in kidney transplant recipients found that higher dietary protein intake was independently associated with a lower risk of moderate and severe fatigue and health-related quality of life, suggesting the need to incorporate nutritional assessment in the diagnostic work-up of fatigue ${ }^{73}$. We note that dietary restrictions that are imposed to limit foods containing high amounts of potassium or phosphorus can worsen malnutrition and negatively affect the quality of life of patients with $\mathrm{CKD}^{74}$. In addition, advanced ageing and comorbid states such as a history of long-standing diabetes mellitus often exacerbate unpleasant symptoms, including frailty, neuropathic pain and cognitive dysfunction.

Inter-individual variation in the reported severity of pain and other symptoms among patients with CKD suggests that both genetic and environmental components may contribute to the perception of symptom unpleasantness. Cultural beliefs and spirituality can also affect the level of discomfort and the motivation to seek medical advice ${ }^{75}$. As discussed below, such differences lead to wide ranges of variability in help-seeking behaviour among patients with unpleasant symptoms ${ }^{76}$.

Numerous reasons may contribute to the variation in the experience of unpleasant symptoms among patients with CKD despite similar and presumably adequate dialysis therapy. For example, differences in metabolomics profiles may have a bearing independent of genetic factors ${ }^{13}$. Alternatively, between-patient differences in the gut microbiome and putative 
modulatory effects of micronutrients may have a role $\mathrm{e}^{77,78}$. As an example, alterations in the metabolism of tryptophan - an essential amino acid that is derived from dietary sources and contributes to the synthesis and regulation of neurotransmitters might contribute to symptoms relating to sleep, mood and pain ${ }^{58,79,80}$, as well as the increased risk of cardiovascular disease ${ }^{81}$ among patients with CKD. Tryptophan is the precursor of a number of signalling molecules, including the neurotransmitter serotonin, the hormone melatonin and vitamin B3 (niacin), all of which have important roles in the regulation of depression and sleep ${ }^{79}$. Alterations in tryptophan metabolism have been implicated in a host of psychoneurological symptoms, including depression, anxiety and pain ${ }^{61,82,83}$. Accelerated tryptophan metabolism is a feature of several clinical conditions including inflammation, infection and malignant disease, and malnutrition associated with alterations in the composition of symbiotic microbiota in the gut. Similarly, patients with CKD demonstrate alterations in tryptophan metabolism as a consequence of inflammatory processes and alterations in enzyme activity ${ }^{81}$.

CKD is associated with increased activity of the indolamine 2,3-dioxygenases 1 and 2 (IDO- 1 and IDO-2), which catalyse the rate-limiting step of L-tryptophan degradation along the kynurenine pathway ${ }^{58,79}$. Although physiological levels of the downstream metabolite kynurenic acid are generally considered to be neuroprotective through antagonism of the $N$-methyl-D-aspartate receptor and a-7-nicotinic acetylcholine receptor ${ }^{58,61,82,84}$, elevated levels of kynurenic acid have been linked to neurological disturbances, including spatial and working memory deficits associated with schizophrenia as a result of reduced dopaminergic and glutaminergic transmission ${ }^{84}$. Additional studies are needed to understand better how the enzymes and products of tryptophan metabolism might be leveraged as biomarkers to monitor disease progression, phenotype symptoms or as biological targets for pharmacological or patient-centred lifestyle interventions.

Alterations in the brain-gut microbiome axis have also been proposed as a mechanism underlying some of the unpleasant symptoms of $\mathrm{CKD}^{85,86}$ (FIG. 3). Microorganisms residing in the gastrointestinal tract, including Lactobacilli, can modulate anxiety and depression-like symptoms by synthesizing

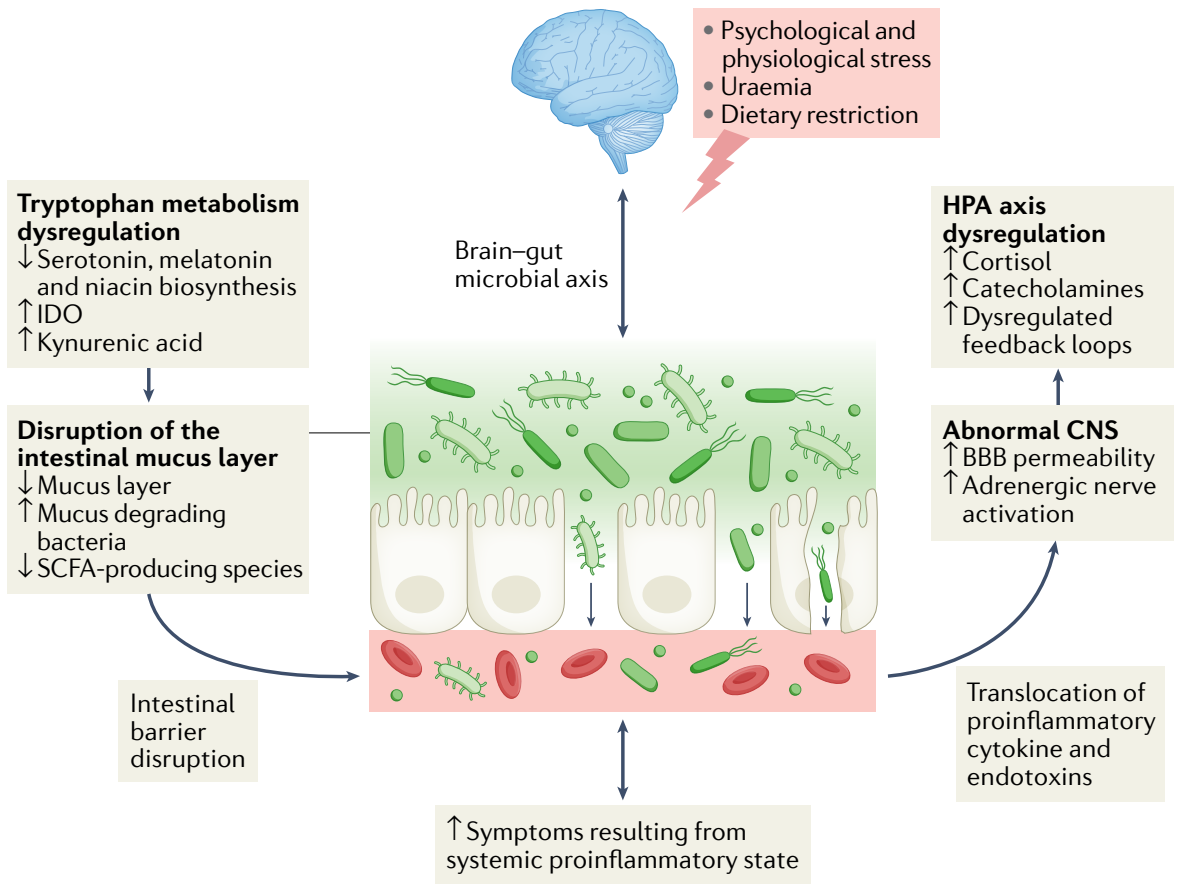

Fig. 3 | Potential role of the brain-gut-microbiome axis in the pathophysiology of CKD-associated symptoms. Uraemic toxins may cause disruption of the epithelial lining of the gastrointestinal tract, leading to translocation of endotoxins and pro-inflammatory cytokines into the circulation, further exacerbating systemic inflammation and related unpleasant symptoms. Intestinal barrier disruption may enhance the production of neuro-modulatory factors by microorganisms residing in the gastrointestinal tract, leading to increased adrenergic nerve activation and dysregulation of the hypothalamic-pituitary axis (HPA), which leads to increased cortisol and catecholamine release, resulting in a dysregulated feedback loop and associated unpleasant symptoms that are experienced by the patient. BBB, blood-brain barrier; CNS, central nervous system; IDO, indolamine 2,3-dioxygenase; SCFA, short-chain fatty acids.

the neurotransmitter $\mathrm{GABA}^{87}$. In addition, butyrate - a byproduct of butyric acid metabolism by gut microbes - has demonstrated antidepressant effects in animal models ${ }^{88}$. The increase in uraemic solutes associated with CKD progression perpetuates a pro-inflammatory state that can cause disruption of the epithelial lining of the gastrointestinal tract. Disruption of the intestinal barrier leads to the translocation of endotoxins and pro-inflammatory cytokines into the circulation, further exacerbating systemic inflammation. Intestinal barrier disruption may additionally enhance the production of neuro-modulatory factors, including GABA and butyrate, and their release into the circulation. Other potential mechanisms include a reduction in species producing short-chain fatty acids, increased blood-brain barrier permeability, increased adrenergic nerve activation and dysregulation of the hypothalamic-pituitary axis, which leads to increased cortisol and catecholamine release, resulting in a dysregulated feedback loop (FIG. 3) ${ }^{89}$. Given the important role of gut microbiota in the synthesis of neuroactive metabolites, strategies to restore gut microbial communities to a 'healthy' state by targeting and promoting beneficial bacteria have ben researched in the past few years and may represent a patient-centred approach to addressing some of the key biological mechanisms and alleviating unpleasant symptoms.

\section{Tools for symptom appraisal in CKD}

Despite the high prevalence of adverse symptoms experienced by patients with $\mathrm{CKD}$, the available evidence shows that these symptoms are often under-recognized and under-treated by clinicians ${ }^{90,91}$. CKD-associated symptoms are often nonspecific, challenging to quantify, and difficult to disentangle from symptoms that result from co-existing comorbidities and medications, which can hinder their detection in the clinical setting. Furthermore, patients with CKD may in some instances under-report their symptoms owing to time constraints on patient-clinician interactions and adaptation to their symptoms, despite ill effects on their well-being. A better understanding of the spectrum of responses 
and help-seeking behaviours of individuals regarding their symptoms and of their perceived level of suffering falls under the domain of symptom appraisal ${ }^{76}$. The process of symptom appraisal aims to assess how unpleasant symptoms are perceived by different patients. For example, some patients may persistently seek help for minor symptoms, whereas others may delay seeking help despite the presence of serious or life-threatening symptoms ${ }^{76}$. In the field of nephrology, different patients may report different levels of unpleasantness and perceived suffering while experiencing the same level of severity of muscle cramps during dialysis treatment. Hence, advancing the scientific rigour behind symptom appraisal is critical to understanding the behaviour of individual patients across a wide spectrum.

Several disease-specific and generic validated tools exist to aid symptom appraisal, although some of these remain under-utilized in the clinical management of CKD (TABLE 3) ${ }^{90,91}$. Generic instruments enable comparisons across different disease states, whereas disease-specific instruments are often used to assess more comprehensively the burden of unpleasant symptoms that are specific to a single disorder. The most frequently used disease-specific symptom assessment tool for patients on dialysis is the KDQOL symptom subscale, which assesses quality of life across 134 different items ${ }^{90}$. However, limitations in its utility as a tool for routine symptom assessment include its incomplete capture of different manifestations and perceptions of symptoms and the fact that it is usually administered by dialysis units on an annual basis (as opposed to weekly to monthly). The Dialysis Symptom Index is another disease-specific validated instrument with which to assess symptoms in patients with $\mathrm{CKD}$, and comprises 30 items that measure the presence and severity of physical and emotional symptoms.

Symptom severity is assessed using a 5-point Likert scale, with each component ranked from 0 to 4 (generating a total score of $0-120$, with higher scores indicating greater symptom burden ${ }^{2}$. In a study of 122 patients on haemodialysis from the prospective, multi-centre 'Malnutrition, Diet and Racial Disparities in Kidney Disease' cohort who underwent protocolized Dialysis Symptom Index assessments, the most prevalent self-reported symptoms included feeling tired/lack of energy (71\%), dry skin (61\%), itching (42\%), muscle cramps (42\%), and numbness/tingling in feet $(41 \%)^{92}$. Patients also reported a high frequency of gastrointestinal issues, mental and/or emotional symptoms, sleep disturbances and pain. Two additional disease-specific instruments include the 'Edmonton Symptom Assessment Revised: Renal' and the Integrated Palliative Care Outcome Scale Renal' symptom assessment tools, which have been adapted from archetypes

Table 3 | Tools for symptom appraisal in CKD

\begin{tabular}{|c|c|c|}
\hline Type of tool & Name of tool & Details \\
\hline \multirow[t]{4}{*}{$\begin{array}{l}\text { Generic } \\
\text { instruments }\end{array}$} & PROMIS-57 & $\begin{array}{l}57 \text { questions across seven quality-of-life } \\
\text { domains (physical function, anxiety, depression, } \\
\text { fatigue, pain, sleep and social functioning) }\end{array}$ \\
\hline & $\begin{array}{l}\text { Memorial Symptom } \\
\text { Assessment Scale }\end{array}$ & $\begin{array}{l}\text { Instrument designed to assess physical and } \\
\text { emotional symptoms experienced by diverse } \\
\text { types of cancer patients }\end{array}$ \\
\hline & $\begin{array}{l}\text { Rotterdam Symptom } \\
\text { Checklist }\end{array}$ & $\begin{array}{l}\text { Tool originally developed to measure the } \\
\text { symptoms reported by cancer patients } \\
\text { participating in clinical research }\end{array}$ \\
\hline & Symptom Distress Scale & $\begin{array}{l}\text { Measures constructs of symptom distress } \\
\text { (degree of discomfort from the specific } \\
\text { symptom as reported by the patient) }\end{array}$ \\
\hline \multirow[t]{4}{*}{$\begin{array}{l}\text { Disease-specific } \\
\text { instruments }\end{array}$} & $\begin{array}{l}\text { Kidney Disease Quality of } \\
\text { Life Instrument (KDQOL) }\end{array}$ & $\begin{array}{l}\text { 134-item instrument, designed to assess } \\
\text { quality-of-life aspects for individuals on dialysis }\end{array}$ \\
\hline & Dialysis Symptom Index & $\begin{array}{l}30 \text {-item survey that assesses physical and } \\
\text { emotional symptoms and their severity }\end{array}$ \\
\hline & $\begin{array}{l}\text { Edmonton Symptom } \\
\text { Assessment Revised: Renal }\end{array}$ & $\begin{array}{l}\text { Modified from the original tool to specifically } \\
\text { assess the physical and emotional symptoms } \\
\text { of patients on dialysis }\end{array}$ \\
\hline & $\begin{array}{l}\text { Integrated Palliative Care } \\
\text { Outcome Scale Renal }\end{array}$ & $\begin{array}{l}\text { 11-item survey that combines the common } \\
\text { symptoms experienced by patients with } \\
\text { additional items (such as information needs, } \\
\text { family anxiety, and so on) }\end{array}$ \\
\hline
\end{tabular}

CKD, chronic kidney disease; PROMIS-57, Patient Reported Outcomes Measurement Information System-57.

in the fields of oncology and palliative care, respectively ${ }^{90,91}$.

Among the arsenal of generic instruments available for symptom appraisal, the NIH Patient Reported Outcomes Measurement Information System (PROMIS-57), is a standardized patient-reported outcomes assessment tool that comprises 57 questions across seven health-related quality-of-life domains (physical function, anxiety, depression, fatigue, pain, sleep disturbance and social functioning), and has demonstrated validity and reliability among kidney transplant recipients $^{52}$.

Further studies are needed to determine the impact of disease-specific and generic tools on the ability of patients and clinicians to identify and reduce symptom burden among patients with $\mathrm{CKD}$ and improve communication between patients, their providers and multidisciplinary teams. The growing body of evidence demonstrating that effective management of symptoms in CKD may lead to improved clinical outcomes including patient survival ${ }^{19}$ suggests that an urgent need exists to increase education and awareness of patients, caregivers and health-care professionals about the importance of routine symptom assessment for patients with CKD.

\section{Management of unpleasant symptoms in CKD}

The burden of CKD and its associated symptoms and management, including complex treatment regimens, medications and their adverse effects, dietary and fluid restrictions, and kidney replacement therapy, can constrain daily living and impair the overall quality of life of patients and their care-partners ${ }^{74}$. This cumulative burden can also negatively impact treatment satisfaction and clinical outcomes ${ }^{93}$. The past few decades have seen very few interventions to improve the quality of life of patients with CKD beyond that of kidney transplantation ${ }^{93}$. Thus, improving research, practice and policy in the field of nephrology requires increased recognition of the need to identify and address patient priorities, values and goals ${ }^{93}$.

These needs are a priority of the World Kidney Day Steering Committee, which selected the theme 'Living well with kidney disease' for its 2021 campaign. This campaign advocated for strengthened partnerships between clinicians and patients to develop, evaluate and implement policy and practice interventions to enable patients to live well with CKD, including prioritization of processes for effective 
symptom management ${ }^{18}$. The involvement of patients and caregivers (or care-partners) in the development of interventions, from priority setting and planning through to dissemination and implementation of the developed tools, is now widely advocated ${ }^{94}$. Some strategies for symptom management are described below ${ }^{95}$.

\section{Incremental dialysis, conservative management and transplantation. Although} dialysis is a lifesaving therapy for patients with advanced CKD, emergent biochemical abnormalities or decompensated volume status, some evidence indicates that dialysis might not benefit all patients and may even be associated with faster eGFR decline in certain groups, including elderly populations and those with multiple comorbidities ${ }^{96}$. Furthermore, an abrupt transition to a thrice-weekly haemodialysis schedule has varying effects on the signs and symptoms of uraemia; it is unknown whether incremental dialysis demonstrates the same variability. Thus, alternative approaches to the abrupt initiation of thrice-weekly dialysis, including the use of incremental dialysis or the implementation of conservative management strategies, including kidney-preserving therapies to delay dialysis initiation, may be worth exploring ${ }^{97}$.

Incremental transition to dialysis therapy (that is, initiating haemodialysis therapies with once- or twice-weekly sessions) might be a better tolerated approach for some patients, compared to the abrupt initiation of thrice-weekly haemodialysis ${ }^{98}$. We consider incremental dialysis to be a patient-centred, tailored approach that takes into consideration the individual's residual kidney function as measured by urine volume or calculated urea clearance of the residual kidneys, and provides symptom relief while minimizing treatment burden $^{99}$. Incremental dialysis initiation may also result in longer preservation of residual kidney function than initiation of thrice-weekly dialysis, which may in turn mitigate dialysis-related symptoms, such as inter-dialytic weight gain and volume overload, loss of appetite and symptoms related to uraemic toxin burden and dietary restrictions ${ }^{100}$. Incremental dialysis regimens can be provided by in-centre facilities or at home ${ }^{101}$. However, larger volume shifts and electrolyte fluctuations should be considered as potential drawbacks of twice-weekly haemodialysis, especially if residual kidney function decreases over time and is not closely monitored ${ }^{102}$. However, incremental transition to peritoneal dialysis and home haemodialysis have benefits beyond the potential preservation of residual kidney function, including greater preservation of the peritoneal membrane and decreased access cannulation, respectively. Randomized, controlled trials that aim to compare the impact of incremental and conventional transition to dialysis on reducing dialysis-related symptoms are ongoing $^{96,103,104}$.

Deferring dialysis initiation with use of conservative management strategies, including kidney-preserving therapies, is another viable treatment option for patients with advanced $\mathrm{CKD}^{97}$. One study suggested that patients with advanced CKD who choose conservative management maintain a better quality of life, although median survival time is shorter compared to that of patients who transition to dialysis ${ }^{105}$. However, incorrect perceptions that conservative management and palliative care in the context of CKD are equivalent to supportive or palliative approaches used for patients in end-of-life or hospice care may deter patients and clinicians from these options ${ }^{7,91,106}$. On the contrary, conservative management of CKD focuses on life-sustaining goals and includes proactive symptom management in the form of CKD-specific palliative care (FIG. 1). The main goals of kidney-preserving therapies are to slow CKD progression; prevent or delay dialysis initiation; and improve cardiovascular health and patient survival ${ }^{97}$. These objectives are consistent with secondary prevention strategies (which aim to slow CKD progression and prolong kidney health) and tertiary prevention strategies (which aim to delay dialysis transition and preserve remaining kidney function) described elsewhere ${ }^{21,107}$. These goals, along with approaches to improve the quality of life of patients with CKD, can be more effectively achieved with concurrent effective symptom management, as shown in studies that have examined the effectiveness of early palliative care on clinical outcomes in other fields such as oncology $y^{108}$. We also believe that conservative and preservative management strategies have the potential to prevent or delay dialysis initiation and its associated symptoms, resulting in favourable health-related quality of life. For example, the judicious use of pharmacotherapies, such as potassium binders and diuretics, as well as avoidance of high dietary protein intake ${ }^{109}$ and an emphasis on plant-based protein sources ${ }^{110}$ can aid in deferring and delaying dialysis by mitigating electrolyte and volume derangements, reducing uraemic toxin production, and ameliorating eGFR decline.
Finally, as the 'gold standard' treatment option for advanced CKD and kidney failure, kidney transplantation confers improved survival over other treatment approaches and often the greatest health-related quality of life. Careful planning and a pro-active approach, particularly if provided pre-emptively prior to prospective dialysis initiation, can enhance the likelihood of successful kidney transplantation. However, patients should be counselled that living related and unrelated kidneys may not be readily available, deceased donor waiting time may be protracted in certain geographic regions, and strict adherence to immunosuppressive medications with potential adverse effects that can lead to unpleasant symptoms is compulsory in those who undergo transplantation. Given these considerations, patients and their care-partners can be reminded that exceptional longevity on dialysis without kidney transplantation is possible, as has been reported in the literature ${ }^{111}$.

\section{Dietary therapy and modulation of the microbiome. Dietary interventions,} including implementation of low-protein diets, may not only slow kidney function decline but may also mitigate CKD-associated symptoms by reducing the generation of uraemic toxins, metabolic acidosis and phosphorus burden ${ }^{110}$. In addition, prioritization of a plant-based diet might also ameliorate CKD-associated symptoms, given that vegetable proteins generate fewer uraemic toxins and have lower phosphorus bioavailability ${ }^{112,113}$.

Given that microorganisms in the human gut have been shown to mediate processes that contribute to symptom burden and are amenable to intervention, they also represent a potential target for symptom management. Many physiological and environmental factors such as diet, host genetics, pollution and antibiotics contribute to the stability of gut microbial communities, and thus have an important role in regulating gut barrier function and immune function ${ }^{114}$. Specifically, adopting a fibre-rich diet rich in fruits and vegetables and avoidance of a 'Western diet' high in animal fats, processed foods, sugar and salt, is essential to maintaining microbiome health and gut barrier integrity ${ }^{115}$.

Interventions that require lifestyle modifications to manage unpleasant symptoms rely heavily on matching the patient's perception of their symptoms with the desired change and therefore require the patient to be involved as a vital part of the treatment team. Adaption and 
integration of the patient's perspective into lifestyle management strategies has great potential to improve symptom outcomes while increasing patient empowerment and patient satisfaction ${ }^{116}$. Disease management strategies with a focus on patient priorities is the foundation of patient-centred symptom management ${ }^{117}$.

\section{Patient choice and shared decision-making.}

Across all of the above-mentioned treatment strategies, prioritization of patient choice using shared decision-making approaches is an essential component of CKD management, including strategies to reduce unpleasant symptoms and suffering ${ }^{7}$. Despite a general lack of innovation in management strategies for kidney failure for decades, the emergence of approaches to promote innovation and expand treatment options beyond traditional pharmacotherapy and conventional dialysis over the past few years have provided patients with opportunities to make informed choices that are aligned with their values, goals and relationships, and may enable patients to maintain hope in the face of organ failure ${ }^{7,101}$. To this end, new policies to support innovative patient-centred approaches should be developed collaboratively by patients and their care-partners, renal support networks, kidney foundations and expert providers. Patient-centred research, including mixed-methods studies, is needed to expand options for the effective management of CKD-associated symptoms, to optimize patient choice and to reinforce patients' quality of life and hope ${ }^{7}$.

\section{Conclusions}

$\mathrm{CKD}$ is associated with unpleasant symptoms that often occur in clusters and are exacerbated by comorbid conditions, pharmacotherapies, lifestyle alterations including dietary restrictions, dialysis therapy, kidney transplantation and ageing. Although uraemic toxins are considered to be the pivotal cause of CKD-related symptoms, treatment of uraemia by dialysis therapy does not necessarily resolve or reduce these unpleasant symptoms. Moreover, dialysis can itself cause additional unpleasant symptoms and worsen health-related quality of life. Given the unintended adverse consequences of our therapeutic arsenal, effective symptom management should include expanded aspects of patient-centred care beyond the traditional treatment of CKD.

Proper implementation of effective symptom management, including CKD-focused palliative care, will require a prominent role of patients and their care-partners in organizing, prioritizing and evaluating care. Partnerships between patients, health-care providers and policymakers across patient care, education, research, service and networking is indispensable as a strategy to overcome the current unmet need for inpatient empowerment ${ }^{27}$. This approach could include, for example, an expanded use of CKD-focused palliative care, so that instead of having a one-time palliative care consultation during an inpatient hospitalization, a dialysis patient or potential dialysis candidate could be evaluated for concurrent symptom management as an outpatient and then during each hospitalization, independent of the severity of illness ${ }^{7}$. Living well with kidney disease with an emphasis on the effective management of unpleasant symptoms should be an urgent goal for the nephrology community.

Kamyar Kalantar-Zadeh (D) 1,2凶, Mark B. Lockwood (D) ${ }^{3}$, Connie M. Rhee ${ }^{2}$, Ekamol Tantisattamo², Sharon Andreoli, Alessandro Balducci ${ }^{5}$, Paul Laffin 6 , Tess Harris [D ${ }^{7}$, Richard Knight ${ }^{8}$, Latha Kumaraswami ${ }^{9}$ Vassilios Liakopoulos (DD ${ }^{10}$, Siu-Fai Luil, 11, Sajay Kumar ${ }^{9}$, Maggie $\mathrm{Ng}^{1,11}$, Gamal Saadi'2, Ifeoma Ulasi' ${ }^{13}$, Allison Tong ${ }^{14}$ and Philip Kam-Tao Li (iD) ${ }^{15 凶}$

'The International Federation of Kidney Foundation World Kidney Alliance (IFKF-WKA), Mexico City, Mexico. ${ }^{2}$ Division of Nephrology and Hypertension and Kidney Transplantation, University of California, Irvine, Irvine, CA, USA.

${ }^{3}$ Department of Behavioral Health Science, University of Illinois at Chicago, College of Nursing, Chicago,

IL, USA.

4James Whitcomb Riley Hospital for Children, Indiana University School of Medicine, Indianapolis, IN, USA.

${ }^{5}$ Italian Kidney Foundation, Rome, Italy.

${ }^{6}$ World Kidney Day Office, Brussels, Belgium.

${ }^{7}$ Polycystic Kidney Disease Charity, London, UK.

${ }^{8}$ American Association of Kidney Patients, Tampa, FL, USA.

${ }^{9}$ Tanker Foundation, Chennai, India.

${ }^{10}$ Division of Nephrology and Hypertension, 1st Department of Internal Medicine, AHEPA Hospital, Aristotle University of Thessaloniki, Thessaloniki, Greece.

\section{"Hong Kong Kidney Foundation, Hong Kong, China.}

${ }^{12}$ Nephrology Unit, Department of Internal Medicine, Faculty of Medicine, Cairo University, Giza, Egypt.

${ }^{13}$ Renal Unit, Department of Medicine, College of Medicine, University of Nigeria, Ituku-Ozalla, Enugu, Nigeria.

${ }^{14}$ Sydney School of Public Health, The University of Sydney, Sydney, New South Wales, Australia.

${ }^{15}$ Department of Medicine and Therapeutics, Carol $\&$ Richard Yu PD Research Centre, Prince of Wales Hospital, Chinese University of Hong Kong, Hong Kong, China.

凶e-mail:kkz@uci.edu; philipli@cuhk.edu.hk https://doi.org/10.1038/s41581-021-00518-z Published online 3 January 2022
1. Lockwood, M. B. et al. Physical symptom cluster subgroups in chronic kidney disease. Nurs. Res. 69 100-108 (2020)

2. Weisbord, S. D. et al. Development of a symptom assessment instrument for chronic hemodialysis patients: the Dialysis Symptom Index. J. Pain. Symptom Manag. 27, 226-240 (2004).

3. Weisbord, S. D. et al. Prevalence, severity, and importance of physical and emotional symptoms in chronic hemodialysis patients. J. Am. Soc. Nephrol. 16, 2487-2494 (2005).

4. Zhang, J. C. et al. Could symptom burden predict subsequent healthcare use in patients with end stage kidney disease on hemodialysis care? A prospective, preliminary study. Ren. Fail. 42, 294-301 (2020).

5. Flythe, J. E. et al. Fostering innovation in symptom management among hemodialysis patients: paths forward for insomnia, muscle cramps, and fatigue. Clin. J. Am. Soc. Nephrol. 14, 150-160 (2019).

6. James, G. et al. Characteristics, symptom severity, and experiences of patients reporting chronic kidney disease in the PatientsLikeMe online health community: retrospective and qualitative study. J. Med. Internet Res. 22, e18548 (2020).

7. Kalantar-Zadeh, K., Wightman, A. \& Liao, S. Ensuring choice for people with kidney failure dialysis, supportive care, and hope. N. Engl. J. Med. 383, 99 (2020)

8. Cabrera, V. J., Hansson, J., Kliger, A. S. \& Finkelstein, F. O. Symptom management of the patient with CKD: the role of dialysis. Clin. J. Am. Soc. Nephrol. 12, 687-693 (2017).

9. Dodd, M. et al. Advancing the science of symptom management. J. Adv. Nurs. 33, 668-676 (2001).

10. Cashion, A. K. $\&$ Grady, P. A. The National Institutes of Health/National Institutes of Nursing Research intramural research program and the development of the National Institutes of Health symptom science model. Nurs. Outlook 63, 484-487 (2015).

11. Cashion, A. K., Gill, J., Hawes, R., Henderson, W. A. \& Saligan, L. National Institutes of Health symptom science model sheds light on patient symptoms. Nurs. Outlook 64, 499-506 (2016).

12. Dorsey, S. G. et al. Working together to advance symptom science in the precision era. Nurs. Res. 68 , 86-90 (2019)

13. Rhee, E. P. et al. Prevalence and persistence of uremic symptoms in incident dialysis patients. Kidney360 1, 86-92 (2020).

14. Saligan, L. N. Collaborative framework to advance symptom science: an intramural perspective. J. Nurs. Scholarsh. 51, 17-25 (2019).

15. Aktas, A., Walsh, D., Hauser, K. \& Rybicki, L. Should we cluster patients or symptoms? The myth of symptom clusters based on 'depression, insomnia, pain' and 'depression, fatigue, pain'. BMJ Support. Palliat. Care 6, 210-218 (2016).

16. Laird, B. J. et al. Pain, depression, and fatigue as a symptom cluster in advanced cancer. J. Pain. Symptom Manag. 42, 1-11 (2011)

17. Abdel-Kader, K., Unruh, M. L. \& Weisbord, S. D. Symptom burden, depression, and quality of life in chronic and end-stage kidney disease. Clin. J. Am. Soc Nephrol. 4, 1057-1064 (2009).

18. Kalantar-Zadeh, K. et al. (World Kidney Day Steering Committee). Living well with kidney disease by patient and carepartner empowerment: kidney health for everyone everywhere. J. Ren. Nutr. https://doi.org/ 10.1053/j.jrn.2020.12.003 (2021).

19. Lockwood, M. B. et al. Symptom cluster science in chronic kidney disease: a literature review. West. J. Nurs. Res. 41, 1056-1091 (2019).

20. GBD Chronic Kidney Disease Collaboration. Global, regional, and national burden of chronic kidney disease, 1990-2017: a systematic analysis for the Global Burden of Disease Study 2017. Lancet 395 709-733 (2020)

21. Li, P. K. et al. Kidney health for everyone everywherefrom prevention to detection and equitable access to care. depression, and fatigue as a symptom cluster in advanced cancer. Clin. Nephrol. 97, 226-232 (2020).

22. DeVon, H. A. et al. Systematic review of symptom clusters in cardiovascular disease. Eur. J. Cardiovasc. Nurs. 16, 6-17 (2017).

23. Sloan, M. et al. Medically explained symptoms: a mixed methods study of diagnostic, symptom and support experiences of patients with lupus and related systemic autoimmune diseases. Rheumatol. Adv. Pract. 4, rkaa006 (2020).

24. Murtagh, F. E. et al. Symptoms in advanced renal disease: a cross-sectional survey of symptom prevalence in stage 5 chronic kidney disease managed 
without dialysis. J. Palliat. Med. 10, 1266-1276 (2007).

25. Almutary, H., Bonner, A. $\&$ Douglas, C. Which patients with chronic kidney disease have the greatest symptom burden? A comparative study of advanced ckd stage and dialysis modality. J. Ren. Care $\mathbf{4 2}$ 73-82 (2016).

26. Dano, S. et al. Evaluating symptom burden in kidney transplant recipients: validation of the revised Edmonton Symptom Assessment System for kidney transplant recipients - a single-center, cross-sectional study. Transpl. Int. 33, 423-436 (2020).

27. Kalantar-Zadeh, K. et al. (World Kidney Day Steering Committee) Living well with kidney disease by patient and care-partner empowerment: kidney health for everyone everywhere. Kidney Int. Rep. 99, 278-284 (2021).

28. Lenz, E. R., Pugh, L. C., Milligan, R. A., Gift, A. \& Suppe, F. The middle-range theory of unpleasant symptoms: an update. Adv. Nurs. Sci. 19, 14-27 (1997).

29. Lee, S. E., Vincent, C. \& Finnegan, L. An analysis and evaluation of the theory of unpleasant symptoms. Adv. Nurs. Sci. 40, E16-E39 (2017).

30. Almutary, H., Douglas, C. \& Bonner, A. Towards a symptom cluster model in chronic kidney disease: a structural equation approach. J. Adv. Nurs. 73 2450-2461 (2017)

31. Linder, L. Analysis of the UCSF symptom management theory: implications for pediatric oncology nursing. J. Pediatr. Oncol. Nurs. 27, 316-324 (2010).

32. Cwiekala-Lewis, K., Parkyn, B. H. \& Modliszewska, K Analysis of University of California in San Francisco (UCSF) symptom management theory and theory implication for persons with neurological disorders/ diseases. J. Neurolog. Neurolosurg. Nurs. 6, 55-65 (2017).

33. Humphreys, J. et al. Middle Range Theory For Nursing. Theory Of Symptom Management 3rd edn Vol. 7 141-164 (Springer, 2014)

34. Almutary, H., Douglas, C. \& Bonner, A Multidimensional symptom clusters: an exploratory factor analysis in advanced chronic kidney disease J. Adv. Nurs. 72, 2389-2400 (2016)

35. Amro, A., Waldum, B., Dammen, T., Miaskowski, C. $\&$ Os, I. Symptom clusters in patients on dialysis and their association with quality-of-life outcomes. J. Ren. Care 40, 23-33 (2014).

36. Miaskowski, C. Future directions in symptom cluster research. Semin. Oncol. Nurs. 32, 405-415 (2016).

37. Kim, H. J., McGuire, D. B., Tulman, L. \& Barsevick, A. M. Symptom clusters: concept analysis and clinical implications for cancer nursing. Cancer Nurs. 28 270-282 (2005)

38. Yu, I. C., Huang, J. Y. \& Tsai, Y. F. Symptom cluster among hemodialysis patients in Taiwan. Appl. Nurs. Res. 25, 190-196 (2012).

39. Ahdoot, R. S., Kalantar-Zadeh, K., Burton, J. O. \& Lockwood, M. B. Novel approach to unpleasant symptom clusters surrounding pruritus in patients with chronic kidney disease and on dialysis therapy. Curr. Opin. Nephrol. Hypertens. https://doi.org/ 10.1097/MNH.0000000000000752 (2021)

40. Lee, S. J. \& Jeon, J. Relationship between symptom clusters and quality of life in patients at stages 2 to 4 chronic kidney disease in Korea. Appl. Nurs. Res. 28, e13-e19 (2015).

41. Amro, A. et al. Symptom clusters predict mortality among dialysis patients in Norway: a prospective observational cohort study. J. Pain. Symptom Manag. 49, 27-35 (2015).

42. Cao, X., Tian, L. \& Lin, C. Symptom clusters in patients receiving haemodialysis: a systematic review of observational studies. J. Clin. Nurs. 26, 2545-2557 (2017).

43. Yong, D. S. et al. Symptom burden and quality of life in end-stage renal disease: a study of 179 patients on dialysis and palliative care. Palliat. Med. 23, 111-119 (2009).

44. Maung, S. C., El Sara, A., Chapman, C., Cohen, D. \& Cukor, D. Sleep disorders and chronic kidney disease World J. Nephrol. 5, 224-232 (2016).

45. Assari, S. \& Burgard, S. Black-white differences in the effect of baseline depressive symptoms on deaths due to renal diseases: 25 year follow up of a nationally representative community sample. J. Ren. Inj. Prev. 4, 127-134 (2015).

46. Murtagh, F. E., Sheerin, N. S., Addington-Hall, J. \& Higginson, I. J. Trajectories of illness in stage 5 chronic kidney disease: a longitudinal study of patient symptoms and concerns in the last year of life. Clin. J. Am. Soc. Nephrol. 6, 1580-1590 (2011).
47. Song, M.-K., Paul, S., Ward, S. E., Gilet, C. A. \& Hladik, G. A. One-year linear trajectories of symptoms, physical functioning, cognitive functioning, emotional well-being, and spiritual well-being among patients receiving dialysis. Am. J. Kidney Dis. 72, 198-204 (2018).

48. Fishbane, S. et al. A phase 3 trial of difelikefalin in hemodialysis patients with pruritus. N. Engl. J. Med 382, 222-232 (2020).

49. Zhang, X., Bansal, N., Go, A. S. \& Hsu, C.-Y. Gastrointestinal symptoms, inflammation and hypoalbuminemia in chronic kidney disease patients: a cross-sectional study. BMC Nephrol. 16, 211-211 (2015).

50. Lockwood, M. B. et al. Symptom cluster science in chronic kidney disease: a literature review. West. J. Nurs. Res. https://doi.org/10.1177/ 0193945918808766 (2018).

51. Tang, E., Bansal, A., Novak, M. \& Mucsi, I. Patient-reported outcomes in patients with chronic kidney disease and kidney transplant. Part 1. Front. Med. 4, 254 (2017).

52. Tang, E. et al. Validation of the Patient-Reported Outcomes Measurement Information System (PROMIS)-57 and -29 item short forms among kidney transplant recipients. Qual. Life Res. 28, 815-827 (2019).

53. Miaskowski, C. et al. Advancing symptom science through symptom cluster research: expert panel proceedings and recommendations. $J \mathrm{NCl}$ https://doi. org/10.1093/jnci/djw253 (2017).

54. Chou, J. A \& Kalantar-Zadeh, K Volume balance and intradialytic ultrafiltration rate in the hemodialysis patient. Curr. Heart Fail. Rep. 14, 421-427 (2017)

55. Kalantar-Zadeh, K. et al. Fluid retention is associated with cardiovascular mortality in patients undergoing long-term hemodialysis. Circulation 119, 671-679 (2009).

56. Chou, J. A. et al. Intradialytic hypotension, blood pressure changes and mortality risk in incident hemodialysis patients. Nephrol. Dial. Transpl. 33 149-159 (2018).

57. Kim, H. J., Barsevick, A. M., Fang, C. Y. \& Miaskowski, C. Common biological pathways underlying the psychoneurological symptom cluster in cancer patients. Cancer Nurs. 35, E1-e20 (2012)

58. $\mathrm{Li}, \mathrm{H}$. et al. Systematic review of the kynurenine pathway and psychoneurological symptoms among adult cancer survivors. Biol. Res. Nurs. 22, 472-484 (2020).

59. Song, B. C. \& Bai, J. Microbiome-gut-brain axis in cancer treatment-related psychoneurological toxicities and symptoms: a systematic review. Support Care Cancer https://doi.org/10.1007/s00520-020-05739-9 (2020).

60. Starkweather, A. R. et al. A conceptual model of psychoneurological symptom cluster variation in women with breast cancer: bringing nursing research to personalized medicine. Curr. Pharmacogenomics Pers. Med. 11, 224-230 (2013)

61. Karu, N. et al. Tryptophan metabolism, its relation to inflammation and stress markers and association with psychological and cognitive functioning: Tasmanian chronic kidney disease pilot study. BMC Nephrol. 17 , 171 (2016).

62. Mihai, S. et al. Inflammation-related mechanisms in chronic kidney disease prediction, progression, and outcome. J Immunol Res. 2018, 2180373 (2018).

63. Meyer, T. W. \& Hostetter, T. H. Uremia. N. Engl. J. Med. 357, 1316-1325 (2007).

64. Sato E. et al. Impact of the oral adsorbent AST-120 on organ-specific accumulation of uremic toxins: LC-MS/ MS and MS imaging techniques. Toxins https://doi.org/ 10.3390/toxins10010019 (2017).

65. Brenner, B. M., Meyer, T. W. \& Hostetter, T. H. Dietary protein intake and the progressive nature of kidney disease: the role of hemodynamically mediated glomerular injury in the pathogenesis of progressive glomerular sclerosis in aging, renal ablation, and intrinsic renal disease. N. Engl. J. Med. 307, 652-659 (1982)

66. Abe, M. \& Kalantar-Zadeh, K. Haemodialysis-induced hypoglycaemia and glycaemic disarrays. Nat. Rev. Nephrol. 11, 302-313 (2015)

67. Besarab, A. \& Coyne, D. W. Iron supplementation to treat anemia in patients with chronic kidney disease Nat. Rev. Nephrol. 6, 699-710 (2010).

68. Chertow, G. M. et al. Self-reported symptoms in patients on hemodialysis with moderate to severe secondary hyperparathyroidism receiving combined therapy with cinacalcet and low-dose vitamin D sterols. Hemodial. Int. 16, 188-197 (2012).
69. Giannaki, C. D. et al. Non-pharmacological management of periodic limb movements during hemodialysis session in patients with uremic restless legs syndrome. ASAIO J. 56, 538-542 (2010).

70. Harri, J., Kasanen, A. \& Pikkarainen, J. The relations between serum ultrafiltrable calcium, acidosis and tetanic symptoms in uremia. Ann. Med. Exp. Biol. Fenn. 41, 15-20 (1963).

71. Rhee, C. M. et al. Thyroid status, quality of life, and mental health in patients on hemodialysis. Clin. J. Am Soc. Nephrol. 12, 1274-1283 (2017).

72. Kim, J. C., Kalantar-Zadeh, K. \& Kopple, J. D. Frailty and protein-energy wasting in elderly patients with end stage kidney disease. J. Am. Soc. Nephrol. 24, 337-351 (2013)

73. Neto, A. W. G. et al. Protein intake, fatigue and quality of life in stable outpatient kidney transplant recipients. Nutrients https://doi.org/10.3390/nu12082451 (2020).

74. Kalantar-Zadeh, K. et al. Dietary restrictions in dialysis patients: is there anything left to eat? Semin. Dial. 28 159-168 (2015).

75. Finkelstein, F. O., West, W., Gobin, J., Finkelstein, S. H. $\&$ Wuerth, D. Spirituality, quality of life and the dialysis patient. Nephrol. Dial. Transplant. 22, 2432-2434 (2007).

76. Petrie, K. J. \& Weinman, J. More focus needed on symptom appraisal. J. Psychosom. Res. 54, 401-403 (2003).

77. Stanford, J. et al. Associations among plant-based diet quality, uremic toxins, and gut microbiota profile in adults undergoing hemodialysis therapy. J. Ren. Nutr. 31, 177-188 (2021)

78. Pignanelli, M. et al. Moderate renal impairment and toxic metabolites produced by the intestinal microbiome: dietary implications. J. Ren. Nutr. 29 55-64 (2019).

79. Davis, I. \& Liu, A. What is the tryptophan kynurenine pathway and why is it important to neurotherapeutics? Expert Rev. Neurother. 15, 719-721 (2015).

80. Kim, H. et al. Brain indoleamine 2,3-dioxygenase contributes to the comorbidity of pain and depression. J. Clin. Invest. 122, 2940-2954 (2012).

81. Ravid, J. D., Kamel, M. H. \& Chitalia, V. C. Uraemic solutes as therapeutic targets in CKD-associated cardiovascular disease. Nat. Rev. Nephrol. 17 402-416 (2021)

82. Chiarugi, A., Calvani, M., Meli, E., Traggiai, E. $\&$ Moroni, F. Synthesis and release of neurotoxic kynurenine metabolites by human monocyte-derived macrophages. J. Neuroimmunol. 120, 190-198 (2001).

83. $\mathrm{Li}, \mathrm{S}$. et al. The role of bacteria and its derived metabolites in chronic pain and depression: recent findings and research progress. Int. $J$. Neuropsychopharmacol. 23, 26-41 (2019).

84. Fujigaki, H., Yamamoto, Y. \& Saito, K. I-Tryptophankynurenine pathway enzymes are therapeutic target for neuropsychiatric diseases: focus on cell type differences. Neuropharmacology 112, 264-274 (2017).

85. Cryan, J. F. \& Dinan, T. G. Mind-altering microorganisms: the impact of the gut microbiota on brain and behaviour. Nat. Rev. Neurosci. 13, 701-712 (2012)

86. Martin, C. R., Osadchiy, V., Kalani, A. \& Mayer, E. A. The brain-gut-microbiome axis. Cell $\mathrm{Mol}$. Gastroenterol. Hepatol. 6, 133-148 (2018).

87. O'Mahony, L. et al. Lactobacillus and Bifidobacterium in irritable bowel syndrome: symptom responses and relationship to cytokine profiles. Gastroenterology 128, 541-551 (2005).

88. Caspani, G., Kennedy, S., Foster J. A \& Swann, J. Gut microbial metabolites in depression: understanding the biochemical mechanisms. Microb. Cell 6, 454-481 (2019).

89. Lau, W. L., Kalantar-Zadeh, K. \& Vaziri, N. D. The gut as a source of inflammation in chronic kidney disease. Nephron 130, 92-98 (2015).

90. Gelfand, S. L., Scherer, J. S. \& Koncicki, H. M. Kidney supportive care: core curriculum 2020. Am. J. Kidney Dis. 75, 793-806 (2020).

91. Zarantonello, D., Rhee, C. M., Kalantar-Zadeh, K \& Brunori, G. Novel conservative management of chronic kidney disease via dialysis-free interventions. Curr. Opin. Nephrol. Hypertens. 30, 97-107 (2021).

92. You, A. et al. Symptom clusters in a diverse prospective hemodialysis cohort. J. Am. Soc. Neph. https://www.asn-online.org/education/kidneyweek/ 2021/program-abstract. aspx? controlld=3612446 (2021) 
93. Tong, A. et al. Implementing core outcomes in kidney disease: report of the Standardized Outcomes in Nephrology (SONG) implementation workshop. Kidney Int. 94, 1053-1068 (2018).

94. The value of engagement. PCORI https://www.pcori. org/about-us/our-programs/engagement/publicand-patient-engagement/value-engagement (2018)

95. Bonventre, J. V. et al. A technology roadmap for innovative approaches to kidney replacement therapies: a catalyst for change. Clin. J. Am. Soc. Nephrol. 14, 1539-1547 (2019).

96. Vilar, E. et al. A multicenter feasibility randomized controlled trial to assess the impact of incremental versus conventional initiation of hemodialysis on residual kidney function. Kidney Int. https://doi.org/ 10.1016/j.kint.2021.07.025 (2021).

97. Kalantar-Zadeh, K., Jafar, T. H., Nitsch, D., Neuen, B. L. \& Perkovic, V. Chronic kidney disease. Lancet 398 , 786-802 (2021)

98. Gedney, N. \& Kalantar-Zadeh, K. Dialysis patient-centeredness and precision medicine: focus on incremental home hemodialysis and preserving residual kidney function. Semin. Nephrol. 38 426-432 (2018)

99. Mathew, A. T., Obi, Y., Rhee, C. M., Chou, J. A \& Kalantar-Zadeh, K. Incremental dialysis for preserving residual kidney function - does one size fit all when initiating dialysis? Semin. Dial. 31, 343-352 (2018).

100. Kong, J. H., Davies, M. R. \& Mount, P. F. The relationship between residual kidney function and symptom burden in hemodialysis patients. Intern. Med. J. https://doi.org/10.1111/imj.14775 (2020).

101. Mehrotra, R. Advancing American kidney health: an introduction. Clin. J. Am. Soc. Nephrol. 14, 1788 (2019).

102. Wong, J., Vilar, E., Davenport, A. \& Farrington, K Incremental haemodialysis. Nephrol. Dial. Transpl. 30 1639-1648 (2015)

103. Murea, M. et al. Renal replacement treatment initiation with twice-weekly versus thrice-weekly haemodialysis in patients with incident dialysisdependent kidney disease: rationale and design of the
TWOPLUS pilot clinical trial. BMJ Open 11, e047596 (2021).

104. Murea, M. \& Kalantar-Zadeh, K. Incremental and twice-weekly hemodialysis program in practice. Clin. J. Am. Soc. Nephrol. 16, 147-149 (2020).

105. Da Silva-Gane, M. et al. Quality of life and survival in patients with advanced kidney failure managed conservatively or by dialysis. Clin. J. Am. Soc. Nephrol. 7, 2002-2009 (2012).

106. Rhee, C. M., Nguyen, D. V., Nyamathi, A. \& Kalantar-Zadeh, K. Conservative vs. preservative management of chronic kidney disease: similarities and distinctions. Curr. Opin. Nephrol. Hypertens. 29, 92-102 (2020).

107. Kalantar-Zadeh, K. \& Li, P. K. Strategies to prevent kidney disease and its progression. Nat. Rev. Nephrol. 16, 129-130 (2020)

108. Parikh, R. B., Kirch, R. A., Smith, T. J. \& Temel, J. S. Early specialty palliative care - translating data in oncology into practice. N. Engl. J. Med. 369, 2347-2351 (2013).

109. Kalantar-Zadeh, K. \& Fouque, D. Nutritional management of chronic kidney disease. N. Engl. J. Med. 377, 1765-1776 (2017).

110. Kalantar-Zadeh, K. et al. Plant-dominant low-protein diet for conservative management of chronic kidney disease. Nutrients 12, 1931 (2020).

111. Yu, J. Z. et al. There's no place like home: 35-year patient survival on home hemodialysis. Semin. Dial. 31, 300-304 (2018)

112. Joshi, S., McMacken, M. \& Kalantar-Zadeh, K Plant-based diets for kidney disease: a guide for clinicians. Am. J. Kidney Dis. 77, 287-296 (2021).

113. Koppe, L. et al. Editorial: a call for a better understanding of the role of dietary amino acids and posttranslational protein modifications of microbiome in the progression of CKD. Nephrol. Dial. Transpl. https://doi.org/10.1093/ndt/gfab033 (2021).

114. Maki, K. A. et al. Considerations when designing a microbiome study: implications for nursing science. Biol. Res. Nurs. 21, 125-141 (2019).
115. Sumida, K., Lau, W. L., Kovesdy, C. P. Kalantar-Zadeh, K. \& Kalantar-Zadeh, K. Microbiome modulation as a novel therapeutic approach in chronic kidney disease. Curr. Opin. Nephrol. Hypertens. 30 75-84 (2021).

116. Coyle, P. K. Symptom management and lifestyle modifications in multiple sclerosis. Continuum 22 815-836 (2016)

117. Humalda, J. K. et al. Self-management approach for dietary sodium restriction in patients with CKD: a randomized controlled trial. Am. J. Kidney Dis. 75, 847-856 (2020).

\section{Acknowledgements}

The authors are supported by research grants from the NIDDK: R03-DK114642 (to C.M.R.), R01-DK122767 (to C.M.R.), R01-DK124138 (to C.M.R and K.K.-Z.), K24-DK091419 (to K.K.-Z.), U01-DK102163 (to K.K.-Z.), R44-DK116383 (to K.K.-Z.). This work was carried out on behalf of the World Kidney Day Steering Committee 2021.

\section{Author contributions}

All authors contributed substantially to discussion of the content, writing the article and/or reviewing or editing the manuscript before submission.

\section{Competing interests}

The authors declare no competing interests.

Peer review information

Nature Reviews Nephrology thanks Gerjan Navis and the other, anonymous, reviewer(s) for their contribution to the peer review of this work.

\section{Publisher's note}

Springer Nature remains neutral with regard to jurisdictional claims in published maps and institutional affiliations.

\section{Supplementary information}

The online version contains supplementary material available at https://doi.org/10.1038/s41581-021-00518-z.

(c) Springer Nature Limited 2022 